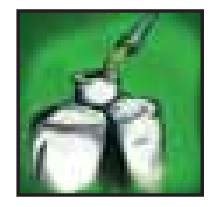

Commentary

\title{
The Big Bang Approach to Health Reform: An Update From the
}

\section{Calgary Regional Health Authority}

\author{
By Hume Martin and Paul Rushforth
}

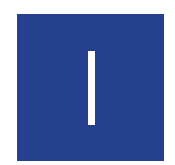
n his 1995 article "Big Bang Health Reform Does It Work? The Case of Britain's 1991 National Health Service Reforms," Rudolf Klein described health reform as one of the worldwide epidemics of the 1990s. Klein's description of the new National Health Service model as a self-inventing institution, coupled with the powerful images on Canadian television in October 1998 of the Calgary General Hospital's implosion, make his article an apt starting point for a preliminary assessment of the impact of health restructuring in Calgary.

In describing Britain's health reform, Klein noted the Thatcher government intentionally resisted formal evaluation of the impact of the changes. The creation of internal markets within the NHS was implemented in a way that frustrated attempts at evaluation.

The Calgary Regional Health Authority (CRHA), believing that the government of Alberta expected a more integrated and fiscally responsible health system, has taken a number of significant actions (exemplified by the fate of the Calgary General Hospital), in response to regionalization. The changes to date in Region 4 (the area served by the CRHA - see map) have been driven by reduced per

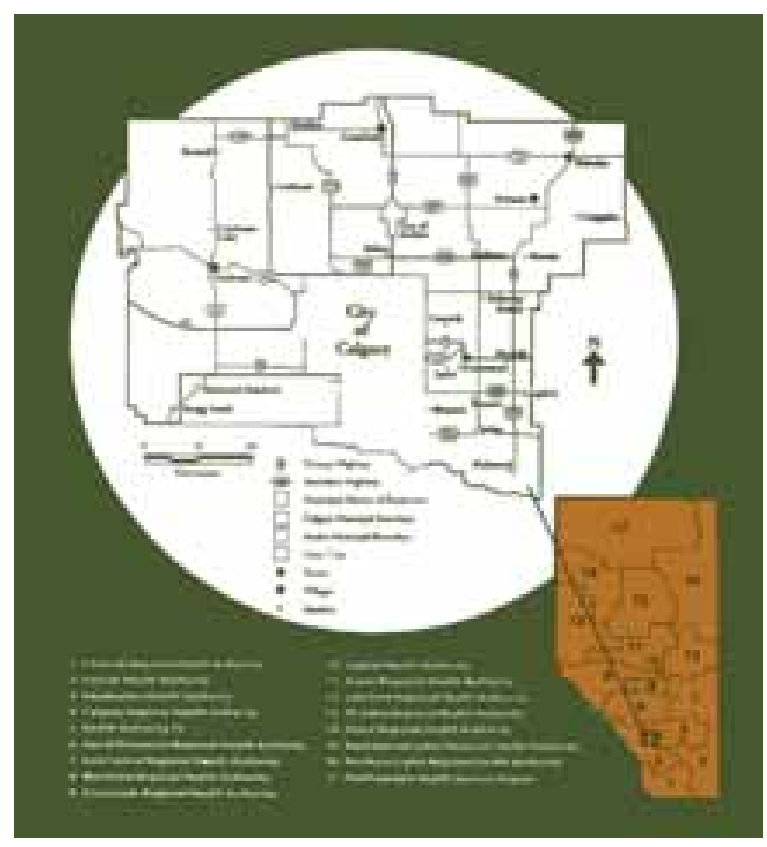

Region 4 surrounds and includes the City of Calgary capita funding, and a commitment to protect quality while creating a foundation that supports a sustainable health system in the future. As was the case in Britain, the absence of a provincial or national system to monitor the impact of regionalization in Canada is striking.

This article will describe health restructuring in Alberta, using the experience of the CRHA to illustrate some successes and ongoing challenges associated with regionalization in one of Canada's fastest-growing urban areas. It will close with a review of some issues associated with the CRHA's effort to fulfill its mandate under the Regional Health Authorities Act which calls for the CRHA to serve as both health system manager at the local level and a major service provider on a broader scale.

\section{Setting the Stage}

In 1992-93, faced with serious financial problems - a deficit of over $\$ 3,000,000,000$ and mounting debts - the government of Alberta decided to tackle restructuring and reduce funding at the same time. In the words of a former Deputy Minister of Health, Alberta "put the brakes on increased funding, reduced administration, and put the major building blocks in place for a new health system." 


\section{Alberta went from being one of the highest per capita spending provinces for health services in the mid-1980s, to one of the lowest.}

The Government of the day found the health system focused on:

- Hospitals and acute care rather than communities and health services;

- Health providers rather than the people who needed health services;

- Illness not health;

- Dollars not outcomes; and

- An environment where costs were mounting with multiple layers of administration and very little accountability.

(Davis 1997)

In 1994 the Government of Alberta passed the Regional Health Authorities Act. Seventeen regional health authorities replaced more than 200 hospital, public-health and long-term care boards. Regional Health Authorities were made responsible for health services ranging from prevention of injury and promotion of wellness to environmental health, home care, long-term care and acute care. Separate provincial health authorities were created to take responsibility for managing mental health and cancer services. Local municipalities maintained responsibility for ambulance services.

Alberta went from being one of the highest per capita spending provinces for health services in the mid-1980s, to one of the lowest. According to the Globe and Mail, between 1991 and 1998 Alberta has had the lowest percentage increase in provincial health spending of any province. Given that Alberta has a relatively young population, age-weighted per capita health funding is now closer to the Canadian average. This is a dramatic change from the mid-1970s to mid-1990s when Alberta had the highest per capita healthcare spending. (CIHI 1997)

\section{The CRHA Response to Regionalization}

In April 1994 Alberta Health issued a three-year business plan. The $\$ 4,000,000,000$ health budget was to be reduced by $17 \%$ with the two largest regions, Edmonton and Calgary, facing a $24 \%$ reduction in operating grants. In Calgary, this translated into a $\$ 143,000,000$ cut to a region that has 800,000 residents and responsibility for providing a range of province-wide services to another 500,000 residents of Southern Alberta. The CRHA also provides secondary and tertiary services to many communities in southeastern British Columbia and south western Saskatchewan.

The Regional Health Authorities Act gave regions extensive responsibility to assess health needs, establish priorities and allocate resources. This legislation requires health authorities to act as the health-system manager for residents of the region it serves. While the Act directs health authorities to ensure that "reasonable access to quality services is provided," it does not specifically require them to provide services beyond priority setting and the preparation of regular health status reports for their region.

The first formal meeting of the new CRHA Board took place in April 1995. The board was made up of 15 community members appointed by the Minister of Health. Three representatives of the medical community, including the Dean of the Faculty of Medicine at the University of Alberta, the Chair of the Medical Advisory board and the President of the Calgary Regional Medical Staff Association, were appointed by the Board as non-voting members. Three other health providers representing the newly formed Health Advisory Council, which is made up of representatives of 50 other health disciplines who are practicing in both hospitals and the community, were also given non-voting seats on the board.

Prior to the creation of the CRHA Board in 1994, there were seven hospital sites operated by five separate boards all with different collective agreements, financial, human resource and clinical information systems. Care centres, home-care and public-health services were also separate entities with their own funding methodologies and information systems. The joint planning that did take place was often frustrated by the lack of support at senior levels. There was limited ability to collect data for the system as a whole. These organizations operated in a transactional environment in which they did their best to respond to service needs. There was little focus on the health needs of defined populations and no impetus to create a more integrated health system.

When the CRHA was formed there were 18,000 employees, 1,750 physicians practicing within the region and an initial budget of $\$ 750,000,000$. The CRHA also assumed responsibility for a large number of continuing-care, homecare, community-rehabilitation, laboratory and selected surgical-service contracts held by its predecessor organizations or transferred to it by Alberta Health. The current value of these contracts is $\$ 223,000,000$.

The existing boards were directed to dissolve by March 1995 and transfer their assets to the CRHA.

\section{Some Eariy Achievements}

The new CRHA Board quickly approved its own three-year business plan to address the service, organizational and financial challenges delegated to it by Alberta Health. This plan called for closure of three of Calgary's seven hospitals and redevelopment of the three remaining adult hospitals.

Within two years and with a $\$ 106,000,000$ capital grant from Alberta Public Works Supply and Services, the three remaining adult hospitals were renovated and expanded to accommodate services transferred from the facilities to be closed. Prior to regionalization, the cost estimates for capital improvements to only two of the previous seven hospitals exceeded $\$ 200,000,000$.

Administrative staffing was cut by $49 \%$. Individual hospital based management structures were eliminated. The region committed itself to pursuing a model described as "one hospi- 


\section{Calgary has a more balanced, responsive and affordable health system than would have been the case had each separate organization independently responded to the funding reductions.}

tal on four sites." The decision made by Alberta Health prior to regionalization to reduce staff salaries and physician fee schedules by five percent was implemented.

Alberta Health established an initial benchmark of 2.4 beds per 1000 population. In 1993 there were 2,350 beds in service in the Calgary region. There are currently 1,845 beds in service. Approximately 1,525 of these beds are available for residents of the region. The remainder support province-wide services and out-of-region patients. With the consolidation of adult-acute services and the decision to recommit to the redevelopment of the Alberta Children's Hospital (a 115-bed facility), the CRHA now has a ratio of 1.7 beds per 1000 population; excluding beds provided for out-of-region residents. This is the same ratio recently reported by the Capital Health Authority in Edmonton (Bear, et al. 1998).

Neuroscience, cardiovascular service and trauma services were consolidated on one site to provide for a sufficient critical mass of staff, service and equipment necessary to support high quality service.

With the support of a major fundraising campaign, all three adult hospitals were provided with CT scanners and two of the four sites received MRI equipment. In addition, the first intraoperative/stroke MRI unit in the world was installed. The Alberta Children's and Foothills Hospitals were accredited as tertiary trauma facilities - the first facilities west of Ontario to receive this designation from the Canadian Trauma Association.

One way of optimizing the use of acute-care facilities was to identify opportunities to move services requiring less expensive infrastructure from hospitals into the community. A few examples of action taken by the CRHA in this regard include:

1. Development of a downtown health centre operated by the CRHA. This was recommended by a task force established to assess the health needs of inner-city residents prior to closure of the Calgary General Hospital in 1997. Originally projected to serve 17,000 patients annually, the 8 th and 8 th Health Centre is expected to receive close to 54,000 visits this year. While services are primarily episodic in nature; they also include child-health services, IV medicine administration and home care. Close links with mental health and addictions service networks are being developed.

2. Creation of Calgary Laboratory Services, a unique public/private partnership that consolidated all hospitaland public- and private-laboratory facilities into a single entity. Close to $\$ 30,000,000$ in annualized savings were achieved by this measure alone.

3. Increases in short-term home care of $121 \%$ since 1994 along with a 50\% service increase for long-term home-care clients.

4. Opening of a regional health centre in Airdrie, a rapidly growing community $20 \mathrm{kms}$ north of Calgary.

5. Development of a Regional Palliative and Hospice Care
Service that brings together community-and facility-based palliative-care providers into a single coordinated service. Service hours in this area have increased by more than $276 \%$ since 1994 . Over the past four years the annual number of supported palliative deaths outside hospitals grew from 373 to 653 ; an increase of over $75 \%$.

6. Establishment of a satellite renal dialysis centre in a shopping mall in the southern end of the City, in response to the annual $15 \%$ increase in the number of residents requiring dialysis.

7. Transfer of the Southern Alberta HIV program into a community setting with a major reduction in hospital utilization.

8. Establishment of an Early Start Parent Information Line. Over 25,000 calls were received in 1997 relating to the health needs of infants from 0 to 2 months of age.

9. Enhancements to the "Best Beginnings" program for at-risk pregnant mothers.

10. Expanded school-health initiatives.

11. Relocation of cardiac rehabilitation services to a community-based recreation facility.

12. Initiation of an aboriginal injury-prevention program.

13. Opening of the University of Calgary/CRHA Community Medicine Clinic at a mall in Calgary's northeast.

14. The establishment of a residential setting for individuals with brain injuries.

15. The development of Royal Park through a unique public/private partnership. The complex houses a continuing-care centre and rental apartments for seniors under one roof. Two new specially designed Alzheimer's Centres will also be opening in 1999 .

The media and many service providers often speak of service cuts. In fact, services have steadily increased, however, owing to tremendous population growth (more than 100,000 additional residents since 1994) these increases still lag somewhat behind service demands. A few examples of service increases include:

- 2,263 cardiac and angiography procedures were performed in 1997 compared to 1,748 in 1993.

- The Home Percenteral Therapy Program provided 2,360 therapy days in its first year of operation in 1992. This year the program is expected to provide 14,000 days of IV therapy at home.

- Emergency-room capacity has increased by $11 \%$.

- 562 trauma patients with an ISS $>16$ were treated in $1997 / 98$ compared to 368 in 1992/93.

- 5,468 clients are now being served in long term care facilities compared to 5,140 in $1992 / 93$.

- The region achieved $95.8 \%$ measles coverage compared to a provincial average of $89.7 \%$. 
- 46,131 doses of flu vaccine were administered in 1996/97 compared to 28,026 in 1992/93. On January 9, 1999, the Calgary Herald reported "With hospitals and other services merged under one authority, the region is far better positioned to respond to a (flu) pandemic than it was before the CRHA was set up in 1994 ... Communication between acute care, continuing care and home care has improved to enable patients to be moved more easily between the various settings." Integrated service delivery in the Calgary region appears to have helped the CRHA cope more effectively with the 1997 flu outbreak than other communities. (Bear, et al 1998)

Other achievements during the first four years of regionalization in Calgary include an extensive region-wide strategic planning process. The region subsequently adopted a plan to support a more comprehensive and integrated system of primary care services. In 1998 Alberta Health decided to invest all federal health-transition funds in the evaluation of a variety of primary healthcare initiatives.

Early evidence of the success of the CRHA's commitment to strengthening linkages between community-based health services is the fact that 11 of the 24 primary-care projects approved in Alberta are located in the area served by the CRHA.

New regional medical staff bylaws were approved in 1997. Nine of the eleven regional clinical department heads are jointly appointed with the University of Calgary. These individuals have responsibility for continuous improvement of the quality and utilization of services in the community as well as in hospital settings. Hospital-based medical advisory boards were subsequently disbanded. This approach is still in its infancy and has received mixed reviews by physicians.

The Population Health Division within the CRHA publishes an annual report on the health status of Region 4 residents. Every three years a more comprehensive health-needs report is completed. The most recent edition of this report is located on the CRHA website at http://www.crha-health.ab.ca. While changes in health services are not a prime factor in determining life expectancy, it is worthwhile to note (see Table 1) that there has been a slight increase in life expectancy in the region over the past four years.

Another notable success has been creation of an Aboriginal Health Council under the auspices of the CRHA Board. This Council has been instrumental in the development of an aboriginal-health representative program to support aboriginal people admitted to hospitals in the region. This is a three-year project jointly funded by the CRHA and Alberta Health. It is intended to enhance the quality of healthcare services that aboriginal patients receive while in hospital. The ultimate goal is to assist aboriginal people in understanding and utilizing the healthcare system and to assist CRHA staff in providing culturally sensitive care. The Aboriginal Health Council has also been active in promoting employment of aboriginals in the health field and recently hosted a successful national conference on aboriginal health issues.

\section{Some Outstanding Challenges}

Outlined below are five areas where the early impact of regionalization has been less than satisfactory.

\section{Medical Staff Engagement}

The changes involved in consolidating hospital services onto four sites disrupted established practice patterns for many physicians. Along with the increasing acuity of hospital patients and the lack of significant changes to fee-for-service physician remuneration, this accelerated the withdrawal of many physicians from hospital service - a situation that had originated before regionalization.

To date, close to 400 of the 800 family physicians practicing in Region 4 have decided not to apply for privileges with the region. As a result, the CRHA has become the first region in Canada to employ hospitalists to take responsibility for the care of patients who do not have an attending physician. Hospitalists are family physicians or internists who are paid by the region to be the physician of record for unattached patients. The region offsets the cost of hospitalists by billing the Alberta Health fee-for-service pool.

It is increasingly difficult for new residents of the region to find family physicians who are accepting new patients. Several pediatricians, psychiatrists and other specialists have also withdrawn from hospital service.

Many physicians privately comment on improvements made possible through the concentration of services such as cardiac surgery, trauma and neurosciences onto single sites. They also comment on the benefit of system-wide care paths for patients in areas such as palliative care, diabetes, thrombolytic therapy and joint disease. Positive comments have also been received about early efforts to develop system-wide standards for laboratory testing.

The primary-care strategy recently approved by the CRHA may re-engage physicians through the collaborative development of effective linkages between primary, secondary and tertiary care. Another step is the establishment of joint risksharing initiatives with physicians interested in pursuing this kind of a relationship. For example, all orthopaedists in Region 4 have expressed interest in working with the CRHA to better manage bone and joint disease.

Staff and physicians in the region are also actively involved in mapping services to see what configuration of primary care, multi-specialist, single specialist and hospital-based groups will best serve populations with different needs within the region in the future. The intent of this planning is to promote physician and provider relationships that optimize the responsiveness of the health system as a whole. 
An alternative, and less satisfactory approach, to physician engagement might be "specialty carve-outs" which are increasingly prevalent in the US. (Herzlinger 1997) These arrangements may offer superior care in selected sub-specialties but have the potential to sub-optimize the larger health system. The development of eye, orthopedic, cardiac, psychiatric and cancer centres with separate governance, capital and operating budgets are examples of this trend in Canada.

TABLE 1

\section{Life Expectancy at Birth Calgary Region 1994-97}

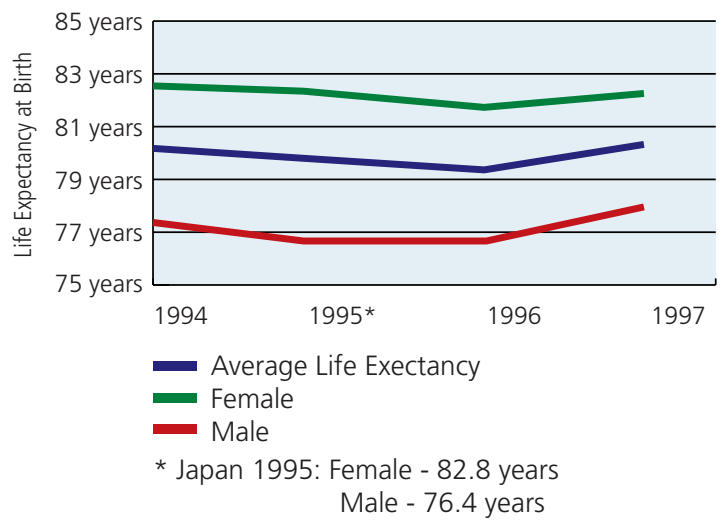

\section{UTILIZATION MANAGEMENT}

Age-standardized patient days per 1000 are not yet reflective of a mature integrated health system. Comparison with other jurisdictions in this area is difficult given that services such as mental health, acute rehabilitation, oncology and obstetrics are often excluded from analysis. Tables 2 and 3 include oncology and obstetrical admissions and compare the utilization performance of the 17 health regions in Alberta with and without acute mental health and rehabilitation admissions.

While the percent decline in the number of patient days per 1,000 for residents of the Calgary region was greater than any other region in Alberta between 1991 and 1997, reductions in the average-length-of-stay during this period were less impressive.

\section{Renewed Growth in Expenditure CuRVE}

The CRHA's recent financial performance shows that notwithstanding significant service consolidation, the expenditure curve is returning to pre-regionalization trends. To a degree, this reflects a larger-than-anticipated population growth in the region over the past four years (see Table 4).

Higher than expected acute-care unit costs have also contributed to this trend. The three remaining adult-acute hospitals experienced massive changes. Programs have been regionalized, relocated and reconfigured. Staff relocated from various sites

Age-Sex Standardized Hospital Days Rates (per 1000 person-years) For Alberta Residents 1991-1997

\begin{tabular}{|c|c|c|c|c|c|c|c|}
\hline \multirow[b]{2}{*}{ RHA } & \multirow[b]{2}{*}{ NAME } & \multicolumn{3}{|c|}{ Without Mental and Rehab Hospitals } & \multicolumn{3}{|c|}{ Including Mental and Rehab Hospitals } \\
\hline & & $91 / 92$ & 96/97 & CHANGE & $91 / 92$ & $96 / 97$ & CHANGE \\
\hline 1 & Chinook & 1472.7 & 872.5 & $-40.8 \%$ & 1498.1 & 881.9 & $-41.1 \%$ \\
\hline 2 & Palliser & 1495.8 & 1100.7 & $-26.4 \%$ & 1526.2 & 1104.7 & $-27.6 \%$ \\
\hline 3 & Head Water & 1336.3 & 824.3 & $-38.3 \%$ & 1358.4 & 844.1 & $-37.9 \%$ \\
\hline 4 & Calgary & 1294.2 & 720.4 & $-44.3 \%$ & 1345.1 & 732.6 & $-45.5 \%$ \\
\hline 5 & Region 5 & 1597.2 & 1015.7 & $-36.4 \%$ & 1625.5 & 1056.0 & $-35.0 \%$ \\
\hline 6 & David Thompson & 1488.5 & 1029.2 & $-30.9 \%$ & 1640.4 & 1158.9 & $-29.3 \%$ \\
\hline 7 & East Central & 1569.7 & 912.9 & $-41.8 \%$ & 1664.0 & 1000.0 & $-39.9 \%$ \\
\hline 8 & Westview & 1247.5 & 745.4 & $-40.2 \%$ & 1351.3 & 844.3 & $-37.5 \%$ \\
\hline 9 & Crossroads & 1414.3 & 930.7 & $-34.2 \%$ & 1518.6 & 1024.1 & $-32.6 \%$ \\
\hline 10 & Capital & 999.3 & 591.4 & $-40.8 \%$ & 1181.3 & 738.5 & $-37.5 \%$ \\
\hline 11 & Aspen & 1428.8 & 1012.4 & $-29.1 \%$ & 1563.2 & 1105.1 & $-29.3 \%$ \\
\hline 12 & Lakeland & 1763.6 & 1011.1 & $-42.7 \%$ & 1879.3 & 1095.5 & $-41.7 \%$ \\
\hline 13 & Nistahia & 1658.4 & 1102.9 & $-33.5 \%$ & 1686.0 & 1134.5 & $-32.7 \%$ \\
\hline 14 & Peace & 1950.8 & 1123.7 & $-42.4 \%$ & 2008.5 & 1156.1 & $-42.4 \%$ \\
\hline 15 & Keeweetinok Lake & 2234.3 & 1368.3 & $-38.8 \%$ & 2332.3 & 1461.1 & $-37.4 \%$ \\
\hline 16 & Northern Lights & 1616.7 & 1332.5 & $-17.6 \%$ & 1640.5 & 1357.2 & $-17.3 \%$ \\
\hline 17 & Northwestern & 2114.1 & 1411.6 & $-33.2 \%$ & 2167.5 & 1504.3 & $-30.6 \%$ \\
\hline
\end{tabular}




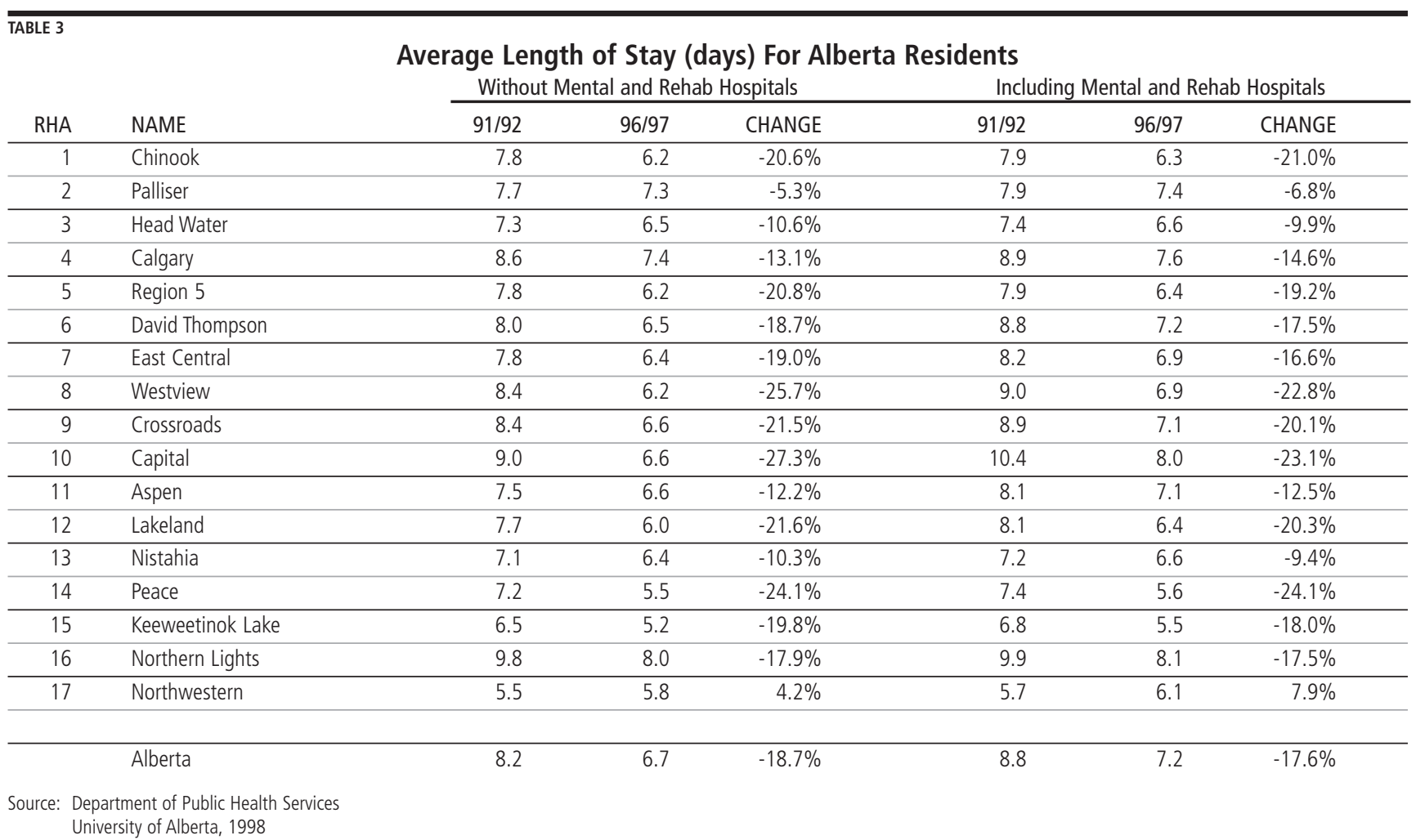

have had to provide services using unfamiliar systems and procedures. Staff from different bargaining unit have had different seniority rights and entitlements. Over a period of four years, and in a volatile labour relations environment, the 37 union certificates that the CRHA inherited have been consolidated into 20 separate certificates. In combination these factors have contributed to some loss of efficiency and added cost.

Table 5 reflects the impact of population growth. It shows that age/sex/inflation/population adjusted per capita spending in Alberta has declined from a peak of $\$ 1687$ per capita in $1982 / 83$ to approximately $\$ 1287$ in $1998 / 99$.

The scope of this paper does not include a detailed review of funding arrangements for regional health authorities. However, in order to understand the challenges faced by the CRHA a brief explanation is required. Funding sources include:

- The CRHA's share of the population-based funding pool for health authorities - The population-based funding model developed by Alberta Health is an allocation rather than a funding model. Funds are allocated to regions through a formula that adjusts for age, gender and socio-economic status. Alberta Health's commitment to the development and evolution of this methodology has supported a population-health focus. The population-based formula has, however, been difficult for the province to implement fully along with the budget cuts that accompanied regionalization. As a result, Alberta Health has maintained a "no loss" provision for Regions that would have experienced further funding cuts through the formula. Regions such as the CRHA, with significant population growth that would have benefited from proportionate per capita funding, have experienced a declining per capita allocation.

- Province-wide services - In 1998/99 the CRHA received $\$ 91,000,000$ for the provision of province-wide services in Southern Alberta. The Capital Health Authority in Edmonton received $\$ 110,000,000$. All liver and heart transplants are done in Edmonton, while bone marrow transplantation takes place in Calgary. Province-wide funding supports high cost, technology intensive services such as dialysis, transplant, neonatology and cardiac services. Concentration of these services in the two large urban regions provides for sufficient volumes to promote high quality, efficient service provision. It also protects smaller regions from the unpredictable charge-back costs through the import/export adjustment of a few "catastrophic" cases.

- Capital grants - Approved projects are funded by government through Alberta Public Works Supply and Services.

- Import/export - This is a year-end adjustment relating to 
residents receiving inpatient services outside their home region. The formula does not yet include ambulatory care except in a limited number of cases where physician billings are used as a proxy service measure.

- Capital equipment funding - Through population-based funds, lottery funds, health foundations and grants that may accompany province-wide services.

- Ancillary and other revenue for uninsured services.

- Donations - From the Calgary Health Trust and the Alberta Children's Hospital Foundation. While there had been some fear that philanthropic revenues would decline, the Calgary Health Trust, created after the merger of five hospital and long-term care foundations, has experienced positive community and corporate support. The Health Trust forecasts a $34 \%$ increase in donations this year.

\section{Limited ShIFT OF Resources to COMMUNity SERVICES}

One of the stated intents of regionalization was to create an environ-

TABLE 4

92/93 -98/99 (projected)

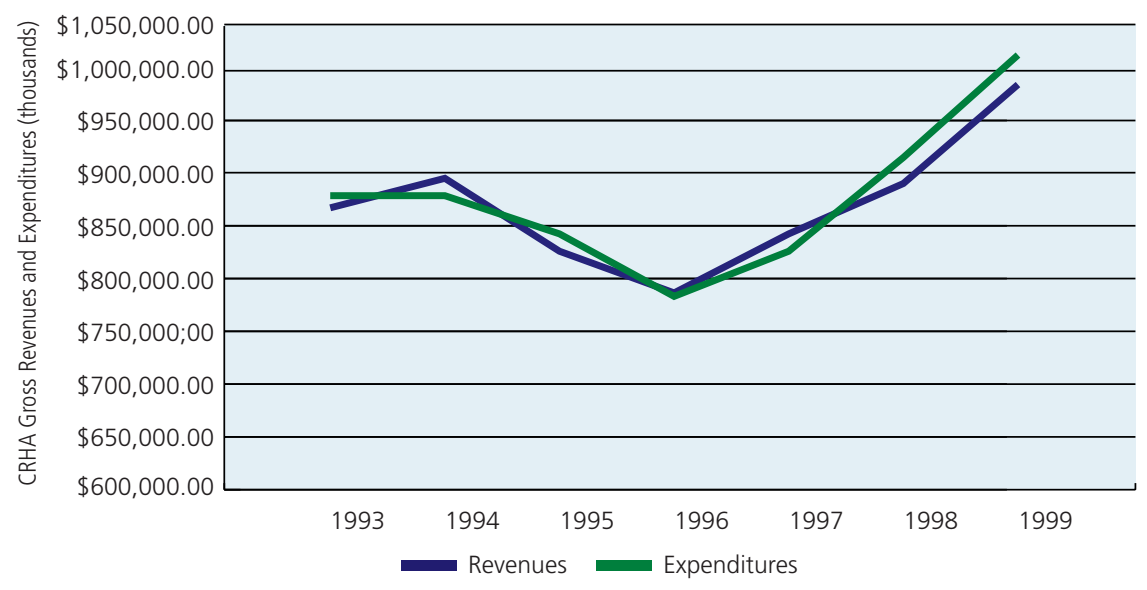

ment where a greater proportion of resources would be allocated to support increased "upstream" capacity. More targeted investment in prevention, promotion and home-care services would help to reduce demand on expensive acute services. Over the past four years the CRHA has increased funding in this area from $\$ 31,700,000$ in $1994-95$ to $\$ 43,900,000$ in $1997-98$. This amounts to $5.1 \%$ of the total operating budget excluding funding for province-wide services. Continued pressures on acute services, the need to maintain public confidence in the health system, together with the need for more cause and effect analysis, has precluded larger investments in community and prevention services.

\section{The Challenge OF}

\section{Defining AdeQuate System CaPACITY}

Members of the CRHA Board frequently communicate their frustration at the lack of clarity regarding the number of acuteand long-term-care beds, palliative-care resources, primary care, rehabilitation and home-care services are needed for the population served by the CRHA. Board members express the need to redefine the term "capacity" and have pushed management to find capacity measures beyond the traditional focus on beds. Health-system managers speak with confidence about capacity in parts of the system, but have more difficulty commenting on the service capacity of the system as a whole. One result of this lack of clarity is the absence of actuarial models that link service requirements to demographic and health status changes.

\section{Lessons Learned and Next Steps}

Some might argue that the challenges listed above bring into question the wisdom of the CRHA approach to

TABLE 5

Alberta Real Funding Per Age/Sex/Inflation/Population Adjusted Capita

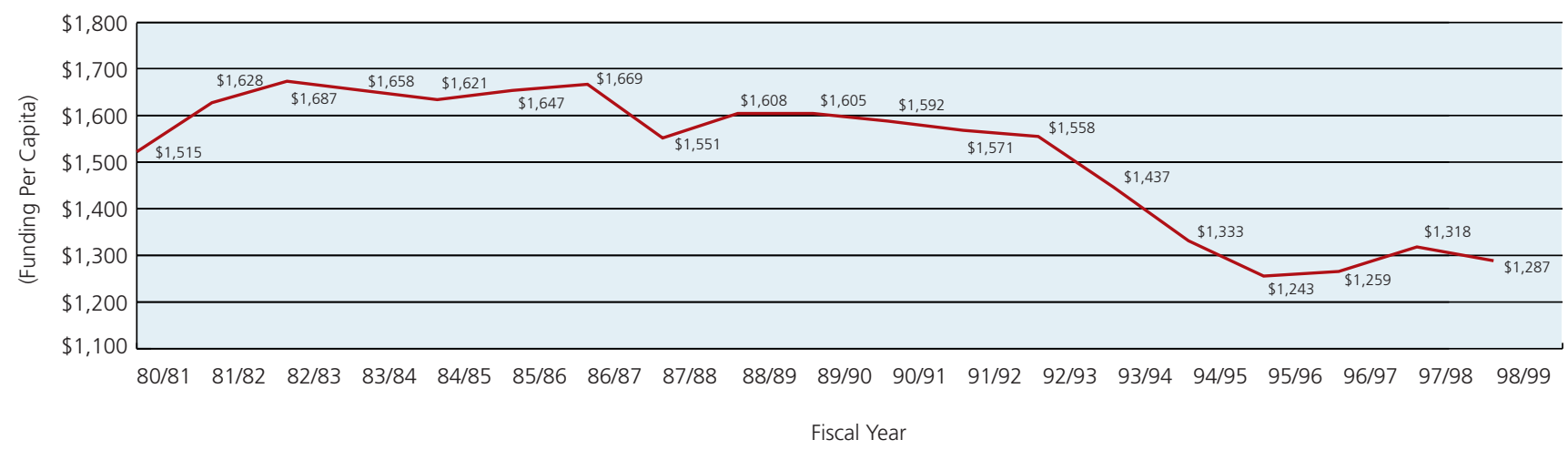


regionalization. Notwithstanding these problems, the vast majority of staff and members of the public with whom the authors have contact state there should be no "going back" to the old system of separate boards and management structures.

Impatience is often expressed at the slow pace of change, pressure on resources and the need for greater clarity in the new roles and relationships. Notwithstanding these frustrations, we need to remember it took decades to create the welter of health services and organizational structures that regions inherited in 1994. A little over four years old, the new regions need time and support to make progress in addressing these issues.

The CRHA moved more quickly to address challenges associated with health system restructuring than many regions in Alberta and other parts of Canada. Hospitals were closed and a new organizational structure created in the expectation that the gulf between demands on the health system and the willingness of the public to pay for services would widen rather than shrink over time.

More attention must be given to the role hospitals will play in a regional health system. Clear links and accountability arrangements need to be developed between community and teaching hospitals, primary care groups, health centres, long term care and rehabilitation facilities and Alberta's recently formed Child and Family Service Authorities.

It is the opinion of the authors that Calgary has a more balanced, responsive and affordable health system than would have been the case had each separate organization independently responded to the funding reductions. Ambulance diversions due to overcrowded emergency departments and cancellation of elective surgery continue to be common in other large cities but exceptional events in Calgary. We firmly believe that health regions can overcome barriers to positive change more effectively than the old system of multiple boards and authorities.

Initial evidence suggests the benefits associated with the Calgary approach outweigh the disadvantages. The absence of a national or provincial framework for health-system performance measurement makes this more speculation rather than fact. Early investment in areas such as system performance measurement, process improvement and system design as well as a balanced reinvestment in health services is required. IG

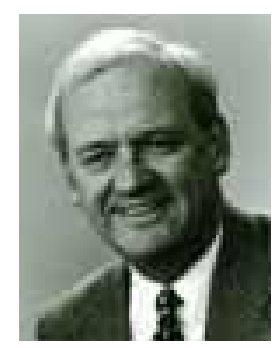

Hume Martin is Chief Regional Officer, Health System Development and Performance, with the Calgary Regional Health Authority. Previously he has served as CEO of the Essex County District Health Council in Windsor Ontario, President of the North York General Hospital in Toronto and Executive HUME MARTIN

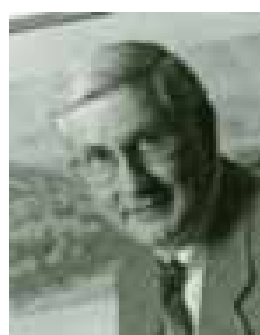

Paul Rushforth is CEO for the Calgary Regional Health Authority. Prior to regionalization, Mr. Rushforth was President of Carewest, a multi-facility long term care organization. He also served as Vice President, Operations, Western Canada for Extendicare.
PAUL RUSHFORTH

\section{REFERENCES}

Bear, Robert, Grant Frame and Sheila Wetherill. 1998. "The Last Critical Care Bed in Western Canada." Healthcare Management Forum. Volume 11, No. 4

Canadian Institute for Health Information (CIHI). 1997. "National Health Expenditure Trends, 1975 1997." p. 73.

Klein, Rudolf. 1995. “Big Bang Health Care Reform - Does It Work?: The Case of Britain's 1991 National Health Service Reforms" The Milbank Quarterly, Vol. 73 No. 3

Jack Davis Insight Conference Proceedings. 1997. "The Alberta Reform Movement Moves Forward Understanding The Direction Of Policy."

Walker, Robert. "Rogue Flu Bugs On Horizon." Calgary Herald, Saturday January 9, 1999.

"Provincial Health Spending 1991/92 to 1998/99 estimate." Globe and Mail. Saturday, December 19, 1998. Herzlinger, Regina. 1997. "What Works: Health Care Focused Factories" Market-Driven Health Care, Addison-Wesley Co. 